\title{
Donor insemination
}

\author{
Melville G Kerr ${ }^{1}$ and Carol Rogers Department of Obstetrics and Gynaecology, McMaster University, \\ Hamilton, Ontario, Canada
}

This paper reviews the technical and social problems concerned in donor insemination in the light of recent developments. The most important of these is the declining number of babies available for adoption by subfertile couples because modern methods and attitudes have reduced the number of unplanned births. At the same time the technique of donor insemination is being developed as public attitudes to it are changing.

This paper makes a number of assumptions. It has been accepted that the facilitation of fertility is legitimate in the face of a population crisis. It is our belief that the needs of world population on the one hand and the expectations of individual couples on the other would both be met if couples could attain but not exceed their desired family size. Furthermore, it has been tacitly assumed that the problems raised here apply only to donor insemination. It could be argued plausibly that similar arguments might apply to other infertility problems, and that the same issues should be considered in selecting patients for tubal surgery or ovulation induction.

Discussions in the recent past have been in the context of a situation where adoption and donor insemination were equally available choices. However, this situation has changed. Adoption is becoming increasingly limited, and there is a compelling need for society to reconsider its attitude to donor insemination. The issue has often been expressed with the overtone that it is doubtful if it is ever legitimate or responsible for a physician to perform donor insemination. The time has come to reverse the thrust of this question and ask if it is responsible for society and its physicians to withhold this form of treatment from couples who may have no other hope of having children.

Artificial insemination is a technique whereby a physician mechanically introduces seminal fluid into the vagina in the hope of producing conception. Insemination using the husband's ejaculate (AIH) is infrequently used because there are very few situations where it is of value. It would be appropriate when the husband is capable of producing

${ }^{1}$ Present address: Department of Obstetrics and Gynaecology, University of Edinburgh. spermatozoa but is incapable of delivering these to his wife's vagina. There are several rare instances $\rightarrow$ of anatomical or functional disturbances of ejacula-? tion where AIH is of some value. Impotence might $\vec{\omega}$ seem to be another example but it is almost in- $\stackrel{\rho}{\Omega}$

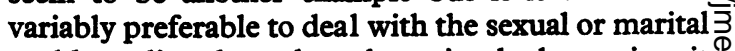
problem directly rather than simply bypassing it ${ }_{-}-$ by artificial insemination. There is a continuing.interest in the use of AIH when the husband can ${ }_{0}$ produce only small numbers of spermatozoa, ando it had been hoped that this technique might improve the results of natural insemination. Publicity has $>$ been given to attempts to collect numbers of such? poor ejaculates, pool these spermatozoa using $\vec{\varphi}$ methods which preserve their activity, ie, freezing of methods, and then re-inject at a later date the larger pooled volume by AIH. Unfortunately, there is still little evidence to support this expectation. At this time, AIH is of very limited value and only in highly selected situations.

The more commonly used type of artificial $\stackrel{\perp}{\perp}$ insemination uses the ejaculate of a selected donor $\overrightarrow{\overrightarrow{0}}$ (AID). The term 'therapeutic donor insemination', $\exists$ or simply 'donor insemination', may be preferable, and the latter term will be used in this paper. $A$ ? third category of artificial insemination is sometimes

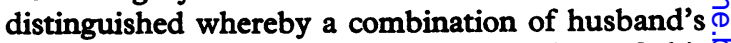
and donor semen is used. But the wisdom of this $\frac{5}{3}$ is questionable. It seems to be a strategy to help a couple to avoid dealing directly with their feelings 0 around the wife's inability to become pregnant and does not merit serious consideration.

\section{Recent developments}

A number of recent developments have forced $a^{N}$ serious reconsideration of the current status of 0 donor insemination. The most compelling of these $\omega$ is the plight of the subfertile couple for whom adoption no longer provides a source of relief. Thereco is no reason to believe that the incidence of infertility is changing significantly, and one can ? assume that approximately ro per cent of all married $\frac{0}{T}$ couples will fail to achieve their desired family size. $\frac{\text { Pे }}{\mathbb{D}}$ Adoption previously represented an acceptable $\stackrel{\mathbb{P}}{\mathscr{Q}}$ alternative for many of these couples. However, this $\stackrel{\square}{\varrho}$ situation has changed dramatically in the last few years. Increasing access to effective contraceptives, $O$ freer availability of sterilization, and increasing useo of legal abortion has reduced the number of un- 
planned births. Furthermore, there is an increasing tendency for unwed mothers to elect to keep their children. Consequently, there has been a drastic reduction in the number of children available for adoption.

At the same time the public's attitude to donor insemination appears to be changing. This has been reflected in public statements by such bodies as the British Medical Association and the American Fertility Society. A British Medical Association Panel on Human Artificial Insemination in 1973 reported favourably on donor insemination, reversing a previous report of a departmental committee of the British government which in 1960 condemned the practice. The American Fertility Society has stated that it accepts donor insemination as a 'recognized medical procedure'. The subject has also been given a fair amount of favourable publicity in the media and this may reflect a change in the attitudes of the public to sexual behaviour. For whatever reason, a greater number of people find the idea of donor insemination acceptable. For some couples donor insemination is regarded only as a second choice when adoption is impossible; for others, however, donor insemination is preferred to adoption.

Furthermore, as this technique is being used more frequently the public is becoming more aware of it. The medical profession is slowly accepting that this is a responsible form of treatment which should be available more widely, and an increasing number of physicians are bringing it to the attention of subfertile couples.

This combination of change in needs, attitudes, and awareness forces a thorough reappraisal of the implications of this technique. It is important that both the medical profession and the lay public should make it the subject of informed study.

Donor insemination requires consideration of a series of problems. There are ethical issues to face and the legal position is unclear and should be clarified. In terms of the medical technique, there are at least three points of controversy - the selection of couples for this form of treatment, the selection of donors, and the potential long-term implications of the development of sperm banks. It is our belief that the selection of donors is not a major problem and has been inflated out of perspective. The implications of sperm banks is undoubtedly important and requires separate discussion. The correct selection of recipients is undoubtedly the major problem in clinical practice.

Relatively little has been written to clarify this area. Criteria for selection have not been clearly identified, and there is no consensus of opinion regarding the most appropriate methods of selection. Yet this should be an area for public discussion, and is one which will benefit greatly from continuing interdisciplinary dialogue and cooperation. The remainder of this paper will concentrate on this issue, after a brief preamble to give an aedquate picture of the practice of donor insemination.

\section{Technique of AID}

It is essentially a simple and successful technique. Donors are recruited and selected on the basis of their willingness to be donors, absence of known illness or heritable undesirable traits, and acceptable quality of seminal fluid. Each recipient is required to keep an accurate menstrual record and an assessment is made of the likely timing of ovulation. Since menstrual cycles are frequently irregular, it is rarely possible to predict the exact timing of ovulation. More commonly, ovulation could occur at any time over a period of three or four days. In such circumstances it is necessary to perform an insemination on two or more occasions in each cycle. A number of techniques can be used to try to pinpoint the time of ovulation more precisely and drugs can sometimes be used to control the timing of the cycle. However, in general, donor insemination has to be performed once or twice each month at a time determined by the length and regularity of the menstrual cycle.

The procedure itself is simple. It simply involves the deposition of fresh seminal fluid in the cervical canal or the upper vagina around the cervix. It is painless and the whole procedure takes about 20 minutes. The success rate depends on the selection of patients but may be as high as 75 per cent. It takes an average of three to four cycles for conception to occur, and can take very much longer.

Although this account emphasizes the simplicity of the technique, it must be appreciated that the procedure is stressful, time consuming and not invariably successful, and this must always be clearly appreciated by couples before they are accepted for this type of treatment. It is rare that a single visit for one treatment leads to immediate conception. More commonly, donor insemination is a tedious, inconvenient, repetitive procedure, punctuated by disappointments, but ultimately successful in a reasonable number of couples.

\section{Selection of recipients}

There are two distinct components in the selection procedure. First, the couple must satisfy medical criteria - this is relatively straightforward, is mainly a matter of medical technology, and will be dealt with only cursorily. Secondly, there is the more difficult area of selecting from couples who satisfy the medical criteria those who are appropriate recipients.

\section{MEDICAL CRITERIA}

Donor insemination is not a panacea for infertility. It is appropriate where the husband is infertile and his wife has no demonstrable bar to conception. The 
husband may produce no sperm and is consequently sterile, or he may have consistently low sperm counts and is therefore significantly subfertile. Less commonly, the male may be normally fertile but be the carrier of a transmissible trait: for example, he may be $R h$ positive with an $R h$-negative wife who has previously had a pregnancy complicated by $\mathrm{Rh}$ immunization; or he may carry a dominant heritable illness, eg, Huntington's chorea.

Conversely, his wife must have been adequately investigated and found to have no impairment to conception. Alternatively she may have a problem which is amenable to treatment. Finally, it should be established that her health is such that a pregnancy would not be contraindicated.

In general, approximately one third of subfertile couples might be expected to fulfil these preliminary medical criteria for further consideration for donor insemination. This indicates the maximum potential. If ro per cent of couples are subfertile, as many as 3 per cent of couples could be candidates for this treatment, although only a minority of these will elect to use it.

\section{NON-MEDICAL CRITERIA}

The problem is, however, infinitely more complex than this medical account might suggest. As a preliminary to further dialogue, we will simply catalogue some considerations which have occurred in our own experience, and follow these with a tentative proposal for a selection process.

The following points are not listed in order of importance.

I The husband's infertility may be associated with a more general illness which jeopardizes his health and life. For example, a man may have had his testes removed for testicular cancer which both removes his fertility and also threatens his life; he may have had treatment for other types of cancer or for other serious diseases, such as some types of kidney disease, which have the same dual effect; a disease process, such as severe diabetes, may threaten his life and render him infertile; paraplegia may seriously incapacitate him and also render him infertile.

We have not taken a rigid opposition with these patients. Where the man's life is currently threatened we have advised that any decision regarding donor insemination should be delayed until the crisis is resolved. However, we have accepted couples even when a husband is incapacitated or whose long-term future is uncertain - provided that the situation has been openly discussed and clearly understood by both husband and wife.

2 The wife's health should not compromise the outcome of pregnancy and her life expectancy should be reasonable. For example, we would probably not undertake donor insemination in a woman with severe diabetes, because of the deleterious effects of severe diabetes on pregnancy and because her own prognosis may be guarded? There may even be a maternal age factor to con sider, and one would be guarded in accepting के woman over 37.

3 The couple must have a stable, matur $\vec{\xi}$ relationship. We would at present consider only married heterosexual unions, and would nof consider either single women or lesbian couples a prospective parents.

4 The couple must be seen to communicate freely and honestly with each other. They should have discussed their feelings about their fertility $\vec{D}$ status and have reached a common ground of agreement.

5 The man should have come to terms with the fact of his subfertility, and should not feel hiș masculinity threatened. He must be tolerant of the idea of not being the biological father of his child $\vec{\omega}$ and have an appreciation that it is in the social role of fatherhood that fulfilment lies rather than in the biological role.

6 The woman should equally have come to terms with the infertile status of the marriage. She should have accepted the fact of her husband's inability too잉 inseminate her successfully and have been able tợ express and deal with her consequent feelings. The wife must not be using a demand for donor in semination as revenge for her husband's failure to give her a child.

7 The couple's motivation for children is likely to be complex and not always easy to elucidate However, it should be based on a mature judgment $\frac{O}{3}$ and not simply be a response to peer or parenta pressures. A pregnancy should certainly not be sought as a means of holding together an unstable marriage. Both members of the couple should share the desire for a child.

8 The couple must be fully informed about al $\mathrm{B}$. aspects of AID - particularly the practical logistics: chances of success or failure; legal implications; the fact that the wife has no greater but no lesser risk of having an abnormal child or a miscarriage than any other pregnant woman.

9 They should have dealt with any moral of religious scruples about all aspects of donop insemination and be sure about their commitment

Io They should not be overly concerned about donor selection. If the child must have certain specific physical characteristics or mental capabilities, then this couple may have not fully come togrips with donor insemination. A sense of completes trust must be present between the couple and the team. If this is lacking donor insemination should 6 not be attempted.

\section{Methods for selection of recipients}

Since these criteria for acceptance are clearly ilb defined and subjective, they are difficult to applys in the clinical situation. It is unfortunate that littleo 
has been written on the subject, and there is no scientific evidence on which to base an opinion. Several general statements have been made that there are no more grateful parents than 'AID parents', and the breakdown of marriages after donor insemination is very low. However, the reliability of these data is in doubt, and there is no evidence as to how these excellent results are achieved. Furthermore, there are several published case reports of psychiatric illnesses which have been attributed to AID, and nothing is known about the outcome in those couples where AID is refused. There is a clear need for guide lines for the selection of recipients, and a comprehensive, long-term follow-up study is required to assess the results of any policy.

On the basis of a very limited experience, with only limited short term follow-up impressions, we would hazard a few guide lines.

I All infertility interviews, and particularly those where donor insemination might become relevant, must deal with couples, rather than simply with wife or husband. Joint involvement must be emphasized from the beginning.

2 Interviews with couples are best carried out by a pair of interviewers, preferably male and female, who have experience in working as a team. This does not imply that an opportunity is not given for individual interviews with each partner.

3 When the question of donor insemination is under consideration, there should never be any tendency to make a hasty decision at one visit. Interviewers may feel under pressure, but this has to be resisted. There is, in fact, positive value in insisting on a delay between interview and implementation - a few months' delay allows time for reconsideration, and many couples have later stressed the value of this waiting time.

4 An infertility team should have access to consultants who can advise on decisions regarding donor insemination. In setting up an appropriate mechanism several problems arise. At one extreme, a physician may feel that he is best equipped to make decisions regarding his patients and may resent any attempt to delegate responsibility. At the other pole, donor insemination could be assigned to such an agency as an adoption society, since they have the benefit of long experience with the related problem of adoption. Our own preference is for an intermediate position where the physician recognizes the need for assistance but remains an integral member of the team.

Two models suggest themselves. The basic infertility group might interview all couples and refer only problem patients to a consultant group. This implies that they can always recognize problems, and it may underestimate the need for the consultant group to gain wider experience in this area. Consequently, an alternative model would be for the entire group to participate in all decisions regarding donor insemination. Such a group should certainly include a psychiatrist and social worker experienced in problems of human reproduction. A clergyman with suitable interest and training may prove a useful member in discussions of ethical issues and a lawyer could provide material as a guideline for legal questions.

Such a group should assume three functions: to improve the accuracy of prediction as to how couples can handle donor insemination; to provide expert resources for couples in dealing with unresolved questions and difficulties; and to follow up their patients over an adequate period to assess the validity and accuracy of their judgments. 